\title{
Pituitary Stalk Interruption Syndrome in a 54-year Adult Male
}

\author{
Wen Wen-Lu, Xiao Fen-Fan, Guo You-Yu and Guo Lin-Wu \\ Department of Traditional Chinese Medicine, The First Affiliated Hospital of Medical College of Zhejiang University, Hangzhou, \\ Zhejiang, China
}

\begin{abstract}
Pituitary stalk interruption syndrome (PSIS) is a rare disease with isolated growth hormone deficiency or multiple anterior pituitary hormone deficiencies; and is characterised by a thin or absent pituitary stalk, hypoplasia of the adenohypophysis, and ectopic neurohypophysis. The literature have reported primarily on cases of infants and young people, and there are few reports in adults. A case is presented here of a 54-year male, who reported dizziness accompanied by fatigue and anorexia for more than 20 days; and the results from the blood tests showed a general decline in growth hormone, thyrotropin, and sex hormone levels. On the basis of the medical history, laboratory and imaging examination, a diagnosis of PSIS was made. After treatment, the patient's condition as well as laboratory results returned to normal. In summary, PSIS can also occur in adults. In the suspected cases, magnetic resonance imaging should be done in time to diagnose and manage it appropriately early in the course of the disease.
\end{abstract}

Key Words: Pituitary stalk interruption syndrome, Pituitary hormone deficiency, Adults.

How to cite this article: Lu WW, Fan XF, Yu GY, Wu GL. Pituitary Stalk Interruption Syndrome in a 54-year Adult Male. J Coll Physicians Surg Pak 2022; 32(03):389-391.

\section{INTRODUCTION}

Pituitary stalk interruption syndrome (PSIS) is a rare clinical disease, which is characterised by a thin or absent pituitary stalk, hypoplasia of the adenohypophysis, and ectopic neurohypophysis. The hormones secreted by the hypothalamus cannot be transported to the pituitary by the pituitary stalk, resulting in clinical symptoms. ${ }^{1,2}$ Fujisawa et al. first reported the disease in $1987 .^{3}$ The pituitary magnetic resonance imaging (MRI) is the most important and direct means of examination for the diagnosis of this disease. ${ }^{4}$ The MRI imaging is helpful in correlating the severity of pituitary target hormone deficiencies and can even predict the occurrence and phenotype of PSIS. ${ }^{5}$

In recent years, reports on PSIS cases and on the process of diagnosis and treatment have increased. The understanding of the disease has improved, but research has primarily concentrated on infants and young people, and little information is available on adults with this disease. We, herein, present a case of a 54year male with this syndrome and review the relevant literature.

Correspondence to: Guo Lin-Wu, Department of Traditional Chinese Medicine, The First Affiliated Hospital of Medical College of Zhejiang University, Hangzhou, Zhejiang, China

E-mail:wuguolin28@163.com

Received: December 17, 2019; Revised: May 19, 2020;

Accepted: May 23, 2020

DOI: https://doi.org/10.29271/jcpsp.2022.03.389

\section{CASE REPORT}

A 54-year male reported dizziness accompanied by fatigue and anorexia for more than 20 days. The dizziness was accompanied by headache, fever, and chills. The highest body temperature was $39.0^{\circ} \mathrm{C}$. After several days, the patient's body temperature returned to normal, and the headache was alleviated. However, the dizziness remained regardless of the body orientation and was accompanied by fatigue, loss of appetite, nausea, and vomiting. It was in this condition that the patient came to our hospital for further examination and treatment.

The patient had the following characteristics: height: $172 \mathrm{~cm}$; weight: $55 \mathrm{~kg}$; $\mathrm{T}$ (temperature): $36.2^{\circ} \mathrm{C}$; and blood pressure: $96 / 75 \mathrm{mmHg}$. The skin and sclerae did not show signs of jaundice. Superficial lymph nodes and jugular vein were not enlarged, and the patient's neck was soft. The trachea was aligned in midline, the respiratory sounds of both lungs were clear and dry, and wet rales were not present. Arrhythmia was not observed, and no obvious pathological murmurs were detected in the auscultation of the valves. The abdomen was flat and soft. There was neither tenderness nor rebound pain in the entire abdomen. The spine and limbs were normal, and there was no edema in either of the lower limbs. The nervous system examination wasnormal.

The results from the blood tests showed a general decline in growth hormone, thyrotropin, and sex hormone levels (Tablel).

By using pituitary MRI, we observed a small pituitary volume, located in the saddle bottom, which was clearly flattened; the 
anterior lobe was more obvious, and the posterior lobe showed a high signal. An enhanced scan showed uniform enhancement of the pituitary and there was no abnormally low enhancement signal shadow. The middle of the pituitary stalk was found and showed no obvious thickening. The absence of signal in the middle appeared to be dotted along the $\mathrm{T} 1$ signal shadow. However, the enhanced scan did not indicate any obvious enhancement.

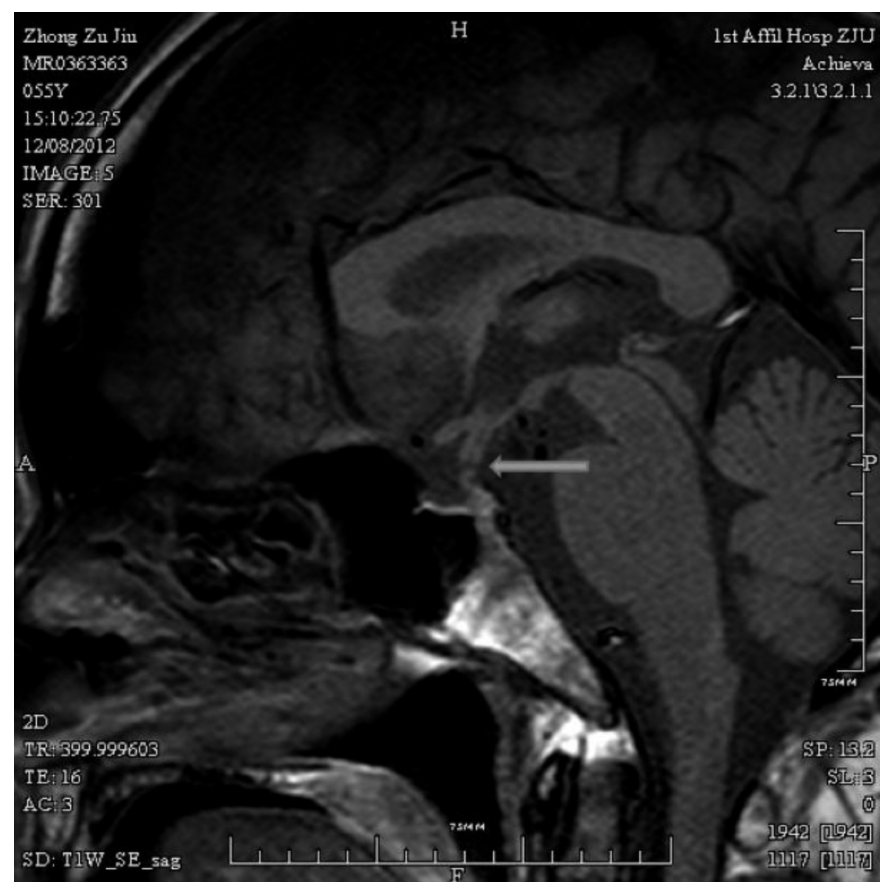

Figure 1: T1 sagittal plain scan showing irregular thickening of the pituitarystalk with interruption of the middle part.

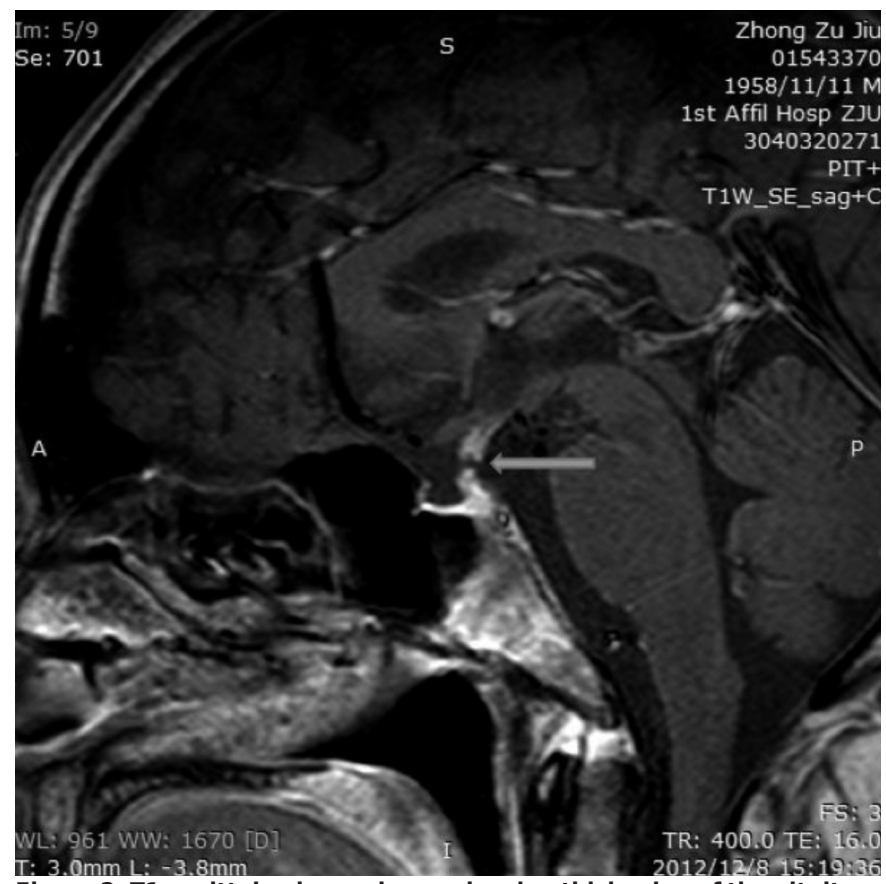

Figure 2: T1 sagittal enhanced scan showing thickening of the pituitary stalkand more clear-cut interruption of the middle part.

Table I: Serum hormones levels.

\begin{tabular}{|c|c|c|}
\hline Hormone & Patient's Result & Normal range \\
\hline Plasma cortisol & $\begin{array}{l}1.06 \mathrm{ug} / \mathrm{dl} \\
(8 \mathrm{am}) \\
1.05 \mathrm{ug} / \mathrm{dl} \\
(4 \mathrm{pm})\end{array}$ & $5.0-25.0 \mathrm{ug} / \mathrm{dl}$ \\
\hline $\begin{array}{l}\text { Serum adrenocorticotropic } \\
\text { hormone }\end{array}$ & $\begin{array}{c}10.9 \mathrm{pg} / \mathrm{mL} \\
(8 \mathrm{am}) \\
11.60 \mathrm{pg} / \mathrm{mL} \\
(4 \mathrm{PM})\end{array}$ & $0.0-46.0 \mathrm{pg} / \mathrm{mL}$ \\
\hline Serum estradiol & $24.2 \mathrm{pg} / \mathrm{mL}$ & $0.0-56.0 \mathrm{pg} / \mathrm{mL}$ \\
\hline Follicular hormone & $0.2 \mathrm{mIU} / \mathrm{mL}$ & $0.7-11.1 \mathrm{mIU} / \mathrm{mL}$ \\
\hline Luteinizing hormone & $0.3 \mathrm{mIU} / \mathrm{mL}$ & $0.8-7.6 \mathrm{mlU} / \mathrm{mL}$ \\
\hline Prolactin & $41.0 \mathrm{ng} / \mathrm{mL}$ & $2.5-17.0 \mathrm{ng} / \mathrm{mL}$ \\
\hline Progesterone & $<0.20 \mathrm{ng} / \mathrm{mL}$ & $0.27-0.90 \mathrm{ng} / \mathrm{mL}$ \\
\hline Human growth hormone & $1.22 \mathrm{ng} / \mathrm{ml}$ & $0.00-0.80 \mathrm{ng} / \mathrm{ml}$ \\
\hline Serum total thyroxine & $29.30 \mathrm{nmol} / \mathrm{L}$ & $\begin{array}{c}55.47-161.25 \\
\mathrm{nmol} / \mathrm{L}\end{array}$ \\
\hline Total triiodothyronine & $0.60 \mathrm{nmol} / \mathrm{L}$ & $1.02-2.96 \mathrm{nmol} / \mathrm{L}$ \\
\hline Third generation thyrotropin & $0.292 \mathrm{mIU} / \mathrm{L}$ & $\begin{array}{c}0.380-4.340 \\
\mathrm{mIU} / \mathrm{L}\end{array}$ \\
\hline Free thyroxine & $7.81 \mathrm{pmol} / \mathrm{L}$ & $\begin{array}{c}10.45-24.38 \\
\mathrm{pmol} / \mathrm{L}\end{array}$ \\
\hline Free triiodothyronine & $1.86 \mathrm{pmol} / \mathrm{L}$ & $2.77-6.31 \mathrm{pmol} / \mathrm{L}$ \\
\hline
\end{tabular}

According to MRI report, the patient was considered to have partial vacuolar sella, shrinkage of the pituitary volume with an absence of signal in the middle of the pituitary stalk, and possible disruption (Figures 1 and 2). Thyroid B-mode ultrasonography indicated $0.6 \times 0.3 \mathrm{~cm}$ hypoechoic nodules in the right thyroid. The diagnosis, based on relevant examination and clinical symptoms, was made of PSIS and hypothyroidism.

The patient was married at the age of 23 years, and his spouse was reportedly healthy. They had one son and one daughter. The parents and children were all healthy, and the height and weight of the family members were normal. The patient had no history of relevant medical or surgical illnesses. In addition, the patient had no history of food and drug allergies, surgery, trauma, blood transfusion, or poisoning.

In the treatment, hydrocortisone tablets with doses of $20 \mathrm{mg}$ (8 $\mathrm{AM}$ ) and $10 \mathrm{mg}$ (4 PM) were given once perday orally, and levothyroxine at a dose of $25 \mu \mathrm{g}$ was given once per day orally. After one week of treatment, the symptoms improved, the patient's sense of well-being and diet improved, the dizziness disappeared, and he showed no nausea and vomiting or other discomforts. On one month follow-up, the adrenocortical function and thyroid function were normal. After six months of follow-up, the patient had a good appetite, no obvious discomfort, an overall weight gain of 10 pounds, and the laboratory examinations were normal.

\section{DISCUSSION}

PSIS is a rare disease with isolated growth hormone deficiency or multiple anterior pituitary hormone deficiencies. It is characterised by a thin or absent pituitary stalk, hypoplasia of adenohypophysis, and ectopic neurohypophysis.

To date, the underlying mechanisms involved in PSIS ontogenesis have remained unclear. Some investigators have reported that PSIS is associated with perinatal abnormalities (breech presentation, cesarean section, preterm birth, and postpartum 
asphyxia) or craniocerebral trauma. ${ }^{6}$

The recent studies suggest that gene mutations during early embryogenesis may be the cause of PSIS. Genes such as PIT1, PROP1, LHX3/LHX4, PROKR2, OTX2, TGIF, and HESX1 may be affected, thus contributing to the disease. ${ }^{2,7}$ Mutations in these genes affect the Wnt, Notch, and sonic hedgehog signalling pathways and the Prokineticin pathway. Reynaud et al. ${ }^{8}$ have analysed the features of 83 patients with PSIS from 80 pedigrees and screened the HESX1, LHX4, OTX2, and SOX3 genes. In that study, the authors found a novel HESX 1 causative mutation in a consanguineous family, as well as two LHX4 mutations present in familial PSIS. In 2015, a mutation in the CDON gene was first reported to be associated with PSIS. ${ }^{9}$ Ender Karaca et al. ${ }^{10}$ have identified a homozygous GPR161 mutation in a family with PSIS. Both GPR161 and CDON genes are involved in the sonic hedgehog signalling pathway, which has been implicated in hypothalamic-pituitary development.

Pituitary MRI is the most important and direct means of examination for the diagnosis of PSIS. ${ }^{4}$ The typical MRI manifestations of PSIS are as follows: the pituitary stalk is absent or thinner; the hypophyseal lobe disappears and is ectopic to the middle of the recess of the third ventricle funnel, a characteristic sign of this disease; and the anterior pituitary shows dysplasia. ${ }^{4}$ Whenever there is clinical suspicion of PSIS, MRI should be ordered in time to make its diagnosis early.

For patients with PSIS, the injured pituitary stalk cannot be recovered through treatment with drugs or surgery. Hormone replacement therapy is the only effective method. ${ }^{1}$ For patients with a deficiency in adrenocortical hormone and thyroxine, corticosteroids should be replaced first or replaced with thyroxine together to avoid acute adrenocortical dysfunction. In this case, oral administration of hydrocortisone tablets and oral levothyroxine tablets were administered in a timely manner, which improved the patient's condition and achieved satisfactory results.

In summary, PSIS not only affects children and adolescents but can also occur in adults. Adults with isolated growth hormone deficiency or multiple anterior pituitary hormone deficiencies should be promptly evaluated by MRI to diagnose the disease early, and starttimely hormonetherapy.

\section{PATIENT'S CONSENT:}

The patient has provided informed consent for publication of the case.

\section{CONFLICT OF INTEREST:}

The authors declared no conflict of interest.

\section{AUTHORS' CONTRIBUTION:}

WWL: Data collection, literature search, and manuscript writing. XF: Data collection.

GY: Data collection, literature search.

GLW: Supervised to write case report.

\section{REFERENCES}

1. Voutetakis A, Sertedaki A, Dacou-Voutetakis C. Pituitary stalk interruption syndrome: cause, clinical manifestations, diagnosis, and management. Curr Opin Pediatr 2016; 28(4):545. doi: 10.1097/MOP.0000000000000378.

2. Wang CZ, Guo LL, Han BY, Su X, Guo QH, Mu YM. Pituitary stalk interruption syndrome: From clinical findings to pathogenesis. J Neuroendocrinol 2017; 29(1). doi: 10.1111/ jne.12451.

3. Fujisawa I, Kikuchi K, Nishimura K, Togashi K, Itoh K, et al. Transection of the pituitary stalk: Development of an ectopic posterior lobe assessed with MR imaging. Radiol 1987; 165(2):487. doi: 10.1148/radiology.165.2.3659371.

4. Xu C, Zhang X, Dong L, Zhu B, Xin T. MRI features of growth hormone deficiency in children with short stature caused by pituitary lesions. Exp Ther Med 2017; 13(6): 3474. doi: 10.3892/etm.2017.4377.

5. Wang Q, Hu Y, Li G, Sun X. Pituitary stalk interruption syndrome in 59 children: the value of MRI in assessment of pituitary functions. Eur J Pediatr 2014; 173(5):589. doi: 10.1007/s00431-013-2214-1.

6. Fernandez-Rodriguez E, Quinteiro C, Barreiro J. Pituitary stalk dysgenesis-induced hypopituitarism in adult patients: Prevalence, evolution of hormone dysfunction and genetic analysis. Neuroendocrinol 2011; 93(3):181. doi: 10.1159/ 000324087.

7. Tatsi C, Sertedaki A, Voutetakis A. Pituitary stalk interruption syndrome and isolated pituitary hypoplasia may be caused by mutations in holoprosencephaly-related genes. J Clin Endocrinol Metab 2013; 98(4):E779. doi: 10.1210/jc.2012-3982.

8. Reynaud R, Albarel F, Saveanu A. Pituitary stalk interruption syndrome in 83 patients: Novel HESX1 mutation and severe hormonal prognosis in malformative forms. Eur J Endocrinol 2011; 164(4):457-65. doi: 10.1530/ EJE-10-0892.

9. Bashamboo A, Bignon-Topalovic J, Rouba H. A nonsense mutation in the hedgehog receptor CDON associated with pituitary stalk interruption syndrome. J Clin Endocrinol Metab 2016; 101(1):12. doi: 10.1210/jc.2015-2995.

10. Karaca E, Buyukkaya R, Pehlivan D. Whole-exome sequencing identifies homozygous GPR161 mutation in a family with pituitary stalk interruption syndrome. J Clin Endocrinol Metab 2015; 100(1):E140. doi: 10.1210/jc. 2014-1984. 